\title{
Primary pancreatic ductal adenocarcinoma cell cultures represent the features of native tumours
}

Marija Ger'

Eglè Žalyt $\dot{e}^{1}$,

Algirdas Kaupinis ${ }^{1}$,

Benediktas Kurlinkus²,

Marius Petrulionis ${ }^{2}$,

Audrius Šileikis²,

Kęstutis Strupas²,

Mindaugas Valius $^{1 \star}$

${ }^{1}$ Proteomics Centre, Institute of Biochemistry,

Vilnius University Life Sciences Centre,

7 Sauletekio Av.,

Vilnius 10257, Lithuania

${ }^{2}$ Institute of Clinical Medicine,

Clinic of Gastroenterology,

Nephrology, and Surgery,

Faculty of Medicine,

Vilnius University,

M. K. Čiurlionio St. 21,

Vilnius 03101, Lithuania
Pancreatic ductal adenocarcinoma (PDAC) is one of the deadliest forms of cancer due to the lack of diagnostic tools at the early stage and low efficiency of current chemotherapeutic approaches. The anticancer compounds with proven efficiency in established cell cultures often fail validation in further research. In this study, we employed PDAC patient-derived primary cell cultures to evaluate the efficiency of chemotherapeutic agents. Alongside, patients' tissue samples were analysed by high-throughput differential proteomic analysis. We have shown that main firstline chemotherapeutic agents gemcitabine and FOLFIRINOX have little to no effect on the viability of patient-derived primary PDAC cells. The comparative proteomic and bioinformatic analysis of PDAC tumours shows an increase in the components of the extracellular matrix and focal adhesions and also overexpression of the downstream signaling from a variety of receptors, most notably PDGF receptor $\beta$ and ErbB1 receptor. Consistently, all tumour-derived cell cultures assayed express a high level of PDGF receptor $\beta$. The enhancement of multiple signaling pathways leads to the increase in cell survival, proliferation, and resistance to apoptosis. Here we demonstrated the promising value of patient-derived primary PDAC cultures as a model for anticancer drug research and evaluation for individualized therapy.

Keywords: pancreatic cancer, patient's primary cell culture, platelet-derived growth factor receptor, neoplasm drug resistance

\section{INTRODUCTION}

Pancreatic cancer is one of the most fatal cancers. The five-year survival rate for pancreatic cancer in the United States was reported at $8 \%$, which was

\footnotetext{
*Corresponding author. Email: mindaugas.valius@bchi.vu.lt
}

the lowest among many other common types of cancer (Siegel et al., 2018). Pancreatic cancer is projected to surpass breast, prostate, and colorectal cancers to become the second leading cause of cancer-related death by 2030 in the USA due to the lack of effective screening modalities and low efficacy of conventional treatment strategies ( $\mathrm{Ra}-$ hib et al., 2014). 
Pancreatic ductal adenocarcinoma (PDAC) represents about $90 \%$ of pancreatic cancer cases. Since 1997, gemcitabine monotherapy has been a standard treatment for PDAC, improving symptoms and prolonging survival of PDAC patients (Burris et al., 1997; Ellenrieder et al., 2016). However, the rate of response to gemcitabine varies from 7\% to $23.8 \%$ (Burris et al., 1997; Hoff et al., 2013) in different trials, and overall survival of gemcitabine-treated patients reaches only 6.5 months (Saung, Zheng, 2017). So far, other clinical trials for PDAC treatment have managed to introduce only FOLFIRINOX (a combination of folinic acid, fluorouracil, irinotecan, and oxaliplatin) therapy (Fryer et al., 2011) and gemcitabine combination with nabpaclitaxel (Hoff et al., 2013) as alternative firstline pancreatic cancer treatment, increasing the weighted median overall survival of therapy-eligible patients by three months.

So far, the standard model for PDAC research has mostly been few established pancreatic cancer cell lines. Only 15 cell lines are broadly available for the research. Moreover, such drawbacks of the established cell lines as genetic drift due to a long cultivation time in vitro and self-evident lack of heterogeneity of tumour specimen are now widely acknowledged problems (Pan et al., 2009; Rückert et al., 2012). Primary tumour-derived cell cultures are gaining recognition as an attractive alternative for cancer research and advanced applications such as personalized treatment screening (Kodack et al., 2017).

In this study we introduced primary patient-derived PDAC culture as a model system for pancreatic cancer treatment evaluation. We demonstrated the lack of efficiency of conventional chemotherapeutic regimens and analysed the molecular mechanisms of innate PDAC drug resistance.

\section{MATERIALS AND METHODS}

\section{Establishment of primary cell lines from surgical samples}

All cell lines were derived from pancreatic adenocarcinoma tumour tissue. After washing three times with PBS, tumour samples were minced with scalpel into $1 \mathrm{~mm}^{3}$ fragments, which were then transferred to culture dishes containing Iscove's Modified Dulbecco's Media (Gibco), 15\% fetal bovine serum (Gibco), and 1\% penicillin/ streptomycin (Gibco), and allowed to adhere. After several weeks, the cells outgrew primary tumour and the first passage was performed. After that, cells were routinely passaged with $0.25 \%$ trypsin/EDTA (Gibco) up to 12th-15th passage, when they became senescent. All experiments in this study were performed with cells up to the 10th passage. Cancer cells were grown in $37^{\circ} \mathrm{C}$ in a humidified atmosphere with $5 \% \mathrm{CO}_{2}$.

\section{Chemical agents}

Gemcitabine hydrochloride (Sigma), 5-fluorouracil (Accord Healthcare), irinotecan hydrochloride (Sigma), and oxaliplatin (Teva) were used in this study. FOLFIRINOX was prepared by mixing equal concentrations (5, 10 , or $20 \mu \mathrm{M}$ ) of 5 -fluorouracil, irinotecan hydrochloride, and oxaliplatin.

\section{Assessment of cell viability and death}

Cell death after drug treatment was evaluated using acridine orange/ethidium bromide assay. One day before treatment, cells were seeded to 24 -well plates, 16000 cells/well. After $24 \mathrm{~h}$, cells were treated with gemcitabine hydrochloride and FOLFIRINOX for $48 \mathrm{~h}$, stained with $0.1 \mathrm{mg} / \mathrm{ml}$ acridine orange $/ 0.2 \mathrm{mg} / \mathrm{ml}$ ethidium bromide mixture, and observed using a confocal laser scanning microscope (Nikon Eclipse TE2000-S). Cell viability/drug cytotoxicity was determined by counting red (stained with ethidium bromide) and green (stained with acridine orange) fluorescent cells and calculating the ratio of (green-red) : green or red : green cells; for each point, at least 300 cells were counted in three different randomly picked fields of view.

For active caspase-3/7 detection by confocal microscopy, cells were seeded at density 800 cells/chamber on glass chamber slides. The next day cells were treated with $100 \mu \mathrm{M}$ 5 -fluorouracil. After $48 \mathrm{~h}$, live cells were stained with CellTracker Red Dye and CellEvent Caspase-3/7 Detection Reagent (both purchased from Thermo Fisher Scientific) and observed 
using a confocal laser scanning microscope (Nikon Eclipse TE2000-S). Miapaca-2 cells treated with $100 \mu \mathrm{M}$ 5-fluorouracil were used as a positive control.

\section{Patient data and tissue samples}

Tissue specimens from 37 patients were included in the analysis: 19 pancreatic cancer samples, ten samples of chronic pancreatitis, and also eight samples of healthy pancreas tissue that were obtained from specimens after surgery for benign pancreas or duodenum diseases. All patients read and signed the form of informed consent for taking part in the research, approved by the Lithuanian Bioethical Committee (Protocol No. PancCa001-3). The process of freezing the specimens was identical to that described by Börner et al. (Börner et al., 2009). Within less than 10 min after resection, tissue samples were frozen in liquid nitrogen in cryotubes. After transportation period of $10 \mathrm{~min}$, the samples were placed in a freezer and kept at a temperature of $-80^{\circ} \mathrm{C}$.

\section{Proteomic sample preparation and LC-MS analysis}

To examine disease-associated changes in the proteome, high-throughput differential labelfree quantitative proteomic analysis of healthy, pancreatic carcinoma, and pancreatitis patient samples was performed using high-definition mass spectrometry (HDMS) technology. The homogenized samples were lysed using urea/thiourea lysis buffer, prepared for digestion and subsequent LC-MS analysis and liquid chromatography (LC) separation of peptides performed as described previously (Ger et al., 2018). The samples were run in triplicate. Raw data files were processed and searched using ProteinLynx Global SERVER (PLGS) version 2.5.3 (Waters Corporation) as described previously (Ger et al., 2018). UniProtKB/SwissProt human database (2018-02-05) was used for protein identification.

\section{Computational and bioinformatic analysis of proteomic data}

For quantitative analysis of proteome, an increase or a decrease in the protein level of 1.5- fold or more was considered as upregulation or downregulation, respectively, with $p$-value $\leq 0.05$. Enrichment analysis of biological processes in differential proteome was performed on the basis of EnrichR enrichment analysis server (Kuleshov et al., 2016). Enrichment only with $p$-value $\leq 0.05$ was considered significant. Kyoto Encyclopedia of Genes and Genomes (KEGG) pathway (Kanehisa et al., 2016) and National Cancer Institute and Nature Publishing Group Pathway Interaction Database (NCINature PID) (Schaefer et al., 2009) databases were employed for signaling pathway analysis. The protein interaction and expression network was built using GeneMANIA app (3.4.1) (Warde-Farley et al., 2010) on Cytoscape 3.3.0 platform (Shannon et al., 2003); physical interaction and pathways data were used for network generation, no related genes were added to the network.

\section{Western blot}

Cells (70-80\% confluent) were washed three times with $\mathrm{PBS}$ and lysed on ice in $\mathrm{EB}++$ buffer: $10 \mathrm{mM}$ Tris- $\mathrm{HCl}(\mathrm{pH} 7.4), 50 \mathrm{mM} \mathrm{NaCl}$, $5 \mathrm{mM}$ EDTA, $50 \mathrm{mM} \mathrm{NaF}, 2 \%$ Triton X-100, $1 \mathrm{mM}$ PMSF, $20 \mathrm{nM}$ aprotinin, $2 \mathrm{mM} \mathrm{NaVO}_{4}$. Then cell lysates were centrifuged for $15 \mathrm{~min}$ at $20000 \times \mathrm{g}$ at $0^{\circ} \mathrm{C}$. Supernatant was collected and protein concentration was determined by the BCA method. Protein samples $(30 \mu \mathrm{g})$ were subjected to $8 \%$ SDS-PAGE at $5 \mathrm{~mA}$, transferred to polyvinylidene difluoride membrane (BioRad) by wet transfer and blocked in Odyssey blocking buffer in PBS (LI-COR Biosciences). Blots were then probed with anti-PDGFR- $\beta$ antibody (produced in our lab by rabbit immunization with recombinant protein). In addition, the blots were probed with anti- $\beta$-actin antibody (MAB8929, R\&D Systems) for detection of $\beta$-actin as a loading control. Membrane-bound primary antibody of $\beta$-actin was probed with IRDye ${ }^{\varpi} 800 \mathrm{CW}$ Infrared dye conjugated secondary goat anti-mouse antibody (LICOR Biosciences). Primary antibody of PDGFR- $\beta$ was probed with IRDye ${ }^{\oplus} 680 \mathrm{RD}$ Infrared dye conjugated secondary goat anti-rabbit antibody (LI-COR Biosciences). Immunofluorescent signal was 
detected by scanning membranes on Odyssey ${ }^{\circledR}$ Infrared Imaging System (LI-COR Biosciences).

\section{RESULTS}

Primary patient-derived pancreatic cancer cell lines exhibit resistance to conventional chemotherapy regimens

Primary cell cultures were grown from PDAC tumour (designated Paca) or from chronic pancreatitis (designated Pancr) samples. Since gemcitabine and FOLFIRINOX are main firstline chemotherapy options for PDAC (Ellenrieder et al., 2016), we tested their efficiency on primary PDAC cell cultures. Chronic pancreatitis cell culture served as a benign control. Our results show that primary tumour cell cultures (Paca6 and Paca9, derived from two different patients) are highly resistant to both drug regimens (Fig. 1A and B). Although high concentrations of gemcitabine hydrochloride $(100 \mu \mathrm{M})$ or FOLFIRINOX $(20 \mu \mathrm{M}$ of

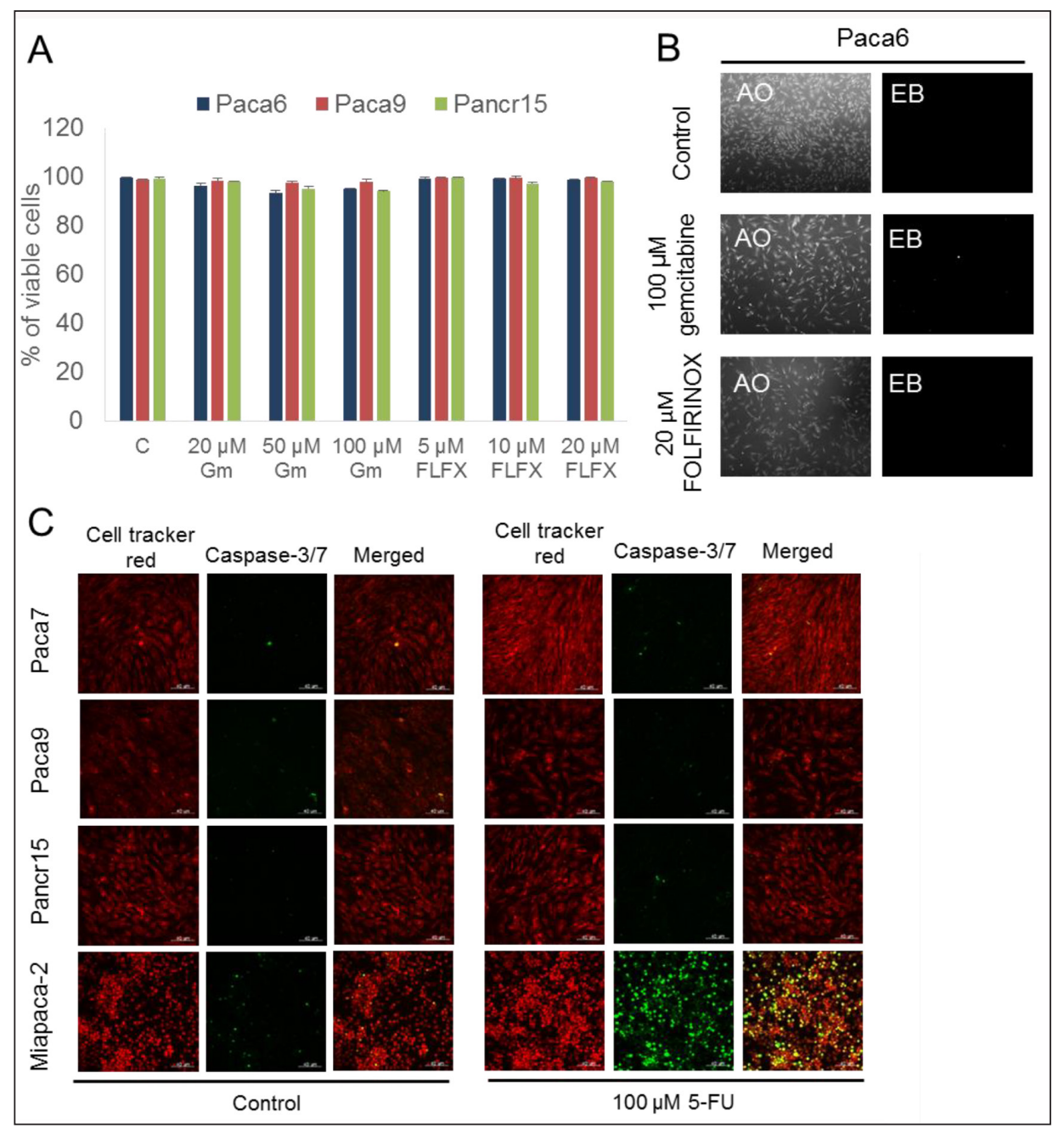

Fig. 1. Conventional anti-PDAC drugs do not induce primary PDAC cell death

A. Paca6, Paca9 and Pancr15 cell viability after 20-100 $\mu$ M gemcitabine and 5-20 $\mu$ M FOLFIRINOX treatment. Cells were exposed to drugs for $48 \mathrm{~h}$, stained with acridine orange and ethidium bromide mixture and counted. Cell viability is expressed as viable cells (100\%-dead cells (stained with ethidium bromide))/all cells (stained with acridine orange).

B. Representative images of Paca6 cells after drug treatment and dual acridine orange/ethidium bromide staining.

C. Caspase-3/7 activation in PDAC cells after 5-fluorouracil exposure. Paca7, Paca9, Pancr15 and Miapaca-2 cells were treated with $100 \mu \mathrm{M}$ 5-fluororuracil for $48 \mathrm{~h}$ and stained with CellTracker Red Dye and CellEvent Caspase-3/7 Detection Reagent. Paca - primary PDAC cell line, Pancr - primary pancreatitis cell line, Gm - gemcitabine hydrochloride, FLFX - FOLFIRINOX, AO - acridine orange, EB - ethidium bromide, 5-FU - 5-fluorouracil. Scale bar, $40 \mu \mathrm{m}$. 
5-fluorouracil, irinotecan hydrochloride, and oxaliplatin) combination visibly slowed down the growth of cell culture, they did not cause cell death after $48 \mathrm{~h}$ treatment. Viability of pancreatitis cell culture Pancr 15 was not affected by the anticancer agents either.

To assay apoptosis induction in primary cell culture, we treated primary tumour cell cultures (Paca7 and Paca9, derived from two different patients), pancreatitis cell culture Pancr15, or the established PDAC cell line MiaPaCa-2 with $100 \mu \mathrm{M} 5$-fluorouracil for $48 \mathrm{~h}$. Caspase $3 / 7 \mathrm{ac}-$ tivity was assayed using CellEvent caspase-3/7 detection reagent (Fig. 1C). 5-fluorouracil caused apoptosis in MiaPaCa-2, but not in primary PDAC or pancreatitis cell lines. No cell death or significant change in caspase activity was detected after a shorter $24 \mathrm{~h}$ treatment. Primary cell lines remained unaffected by 5 -fluorouracil treatment even after a longer $72 \mathrm{~h}$ treatment.

These data show that primary pancreatic cancer cell cultures exhibit innate resistance to gemcitabine and FOLFIRINOX chemotherapy.

\section{Proteomic analysis shows overexpression of multiple signaling pathways in PDAC tissue samples}

To elucidate potential innate drug resistance mechanism, tissue samples from 19 patients with pancreatic cancer and from eight patients with benign pancreas or duodenum conditions were analysed by the protein differential mass spectrometry. The samples were fractionated and analysed by HDMS in two series of proteomic experiments. 3192 proteins in total in all patient proteomes were identified and quantified. Proteins level of which was significantly $(p \leq 0.05)$ increased or decreased 1.5-fold and higher in chronic pancreatitis or PDAC patients versus control pancreatic samples from benign diseases in both series of experiments were considered differentially regulated. In PDAC we found 534 differentially regulated proteins; levels of 343 proteins were increased and of 191 proteins were decreased.

Differential PDAC-specific proteome of 534 proteins was analysed on the base of EnrichR resource. For the analysis of altered cell signaling pathways NCI-Nature Pathway Interaction Database (NCI-Nature PID) was employed. Table 1 shows top 20 signaling pathways enriched in PDAC differential proteome. Overlapping or redundant pathways consisting of same proteins were grouped into clusters (Fig. 2A). Data highlight the dominance of multiple extracellular matrix (ECM) proteins, of integrins that ensure cell interaction with ECM and integrin downstream signaling components. Pathways of integrin-linked kinase (ILK), platelet-derived growth factor receptor $\beta$ (PDGFR $\beta$ ), HIF$1 \alpha$ transcription factor, ErbB1, and chemokine receptor CXCR4 were also overexpressed in PDAC differential proteome.

Metabolic and regulatory processes in differential PDAC proteome were analysed in a similar way using the KEGG Pathways database. Table 2 shows top 20 pathways enriched in PDAC. Overlapping or redundant pathways consisting of same proteins were also grouped into clusters (Fig. 2B). The data show overexpression of focal adhesion components and highlight several related processes. The change in PDAC metabolism, especially enhanced glycolysis and reduction in amino acid metabolism, also in production of pancreatic secretion components, is revealed.

Using combined data from the analysis in NCI-Nature PID and KEGG Pathways database an interactive network of PDAC regulatory processes was built (Fig. 2C). The majority of overexpressed signaling-related proteins belong to ECM, focal adhesion, and integrin interaction network. Overexpressed PDGFR $\beta$ pathway downstream components also comprise a large part of altered proteome. Both integrin and PDGFR $\beta$ signaling are known to ensure cell survival, proliferation, and suppression of apoptosis. Other enriched pathways, such as HIF-1 $\alpha$ transcription factor, ILK, CXCR4, and mTOR-mediated signaling also play a role in innate drug resistance.

Since PDGFR $\beta$ signaling pathway was highly enriched in PDAC tumour proteome, we assayed the expression of PDGFR $\beta$ in a panel of tumour-derived primary cell lines by Western 
Table 1. NCI-Nature PID pathways enriched in PDAC

\begin{tabular}{|c|c|c|c|c|}
\hline No. & Term & $p$-value & \begin{tabular}{|c|} 
Combined \\
EnrichR \\
Score
\end{tabular} & Genes \\
\hline 1 & $\begin{array}{l}\text { Betal integrin cell surface interac- } \\
\text { tions }\end{array}$ & $3 \mathrm{E}-11$ & 41.0 & $\begin{array}{c}\text { LAMB3; FN1; TNC; F13A1; LAMC2; THBS1; COL1A1; } \\
\text { COL3A1; COL5A1; COL6A2; COL6A1; COL4A5; } \\
\text { ITGAV; CD14; TGFBI; TGM2 }\end{array}$ \\
\hline 2 & PDGFR-beta signaling pathway & $3 \mathrm{E}-09$ & 38.4 & $\begin{array}{c}\text { ACTR3; CYFIP2; TAGLN; LRP1; STAT1; ARPC1B; } \\
\text { ACTN4; IQGAP1; YWHAZ; RHOA; ACTA2; RAP1A; } \\
\text { ARPC2; ARPC3; ITGAV; SFN; GRB2; RAC1; YWHAH }\end{array}$ \\
\hline 3 & Integrins in angiogenesis & $1 \mathrm{E}-09$ & 32.6 & $\begin{array}{c}\text { COL14A1; COL12A1; FN1; F11R; RHOA; COL1A1; } \\
\text { COL3A1; COL5A1; COL6A2; COL6A1; COL4A5; } \\
\text { ITGAV; RAC1; TLN1; VCL }\end{array}$ \\
\hline 4 & ErbB1 downstream signaling & 7E-06 & 19.2 & $\begin{array}{c}\text { ACTR3; CYFIP2; STAT1; ARPC1B; PEBP1; IQGAP1; YW- } \\
\text { HAZ; ARPC2; ARPC3; SFN; GRB2; RAC1; YWHAH }\end{array}$ \\
\hline 5 & Integrin-linked kinase signaling & $4 \mathrm{E}-06$ & 18.1 & $\begin{array}{c}\text { XPO1; PARP1; ACTN1; RUVBL1; RAC1; IQGAP1; MYL9; } \\
\text { TNS1; LIMS1 }\end{array}$ \\
\hline 6 & RAC1 signaling pathway & $2 \mathrm{E}-05$ & 15.7 & $\begin{array}{c}\text { ACTR3; CYFIP2; ARPC2; ARPC3; ARPC1B; CFL1; RAC1; } \\
\text { IQGAP1; PAK2 }\end{array}$ \\
\hline 7 & $\begin{array}{l}\text { Signaling events mediated by focal } \\
\text { adhesion kinase }\end{array}$ & $3 \mathrm{E}-05$ & 14.0 & $\begin{array}{c}\text { ACTA1; RAP1A; ACTN1; ITGAV; GRB2; RAC1; TLN1; } \\
\text { RHOA; VCL }\end{array}$ \\
\hline 8 & $\begin{array}{c}\text { amb2 Integrin signaling_Homo } \\
\text { sapiens }\end{array}$ & $1 \mathrm{E}-05$ & 13.8 & $\begin{array}{c}\text { RAP1A; ITGAM; LRP1; MMP2; ITGB2; TLN1; RHOA; } \\
\text { ICAM1 }\end{array}$ \\
\hline 9 & a6b1 and a6b4 Integrin signaling & $3 \mathrm{E}-05$ & 12.4 & $\begin{array}{c}\text { LAMB3; CD9; LAMC2; SFN; GRB2; RAC1; YWHAZ; } \\
\text { YWHAH }\end{array}$ \\
\hline 10 & $\begin{array}{c}\text { Beta2 integrin cell surface interac- } \\
\text { tions }\end{array}$ & $1 \mathrm{E}-05$ & 11.6 & C3; ITGAM; ITGB2; TGFBI; F11R; KNG1; ICAM1 \\
\hline 11 & $\begin{array}{c}\text { Beta3 integrin cell surface interac- } \\
\text { tions }\end{array}$ & $2 \mathrm{E}-05$ & 11.4 & $\begin{array}{c}\text { COL1A1; FN1; TNC; COL4A5; ITGAV; TGFBI; F11R; } \\
\text { THBS1 }\end{array}$ \\
\hline 12 & $\begin{array}{c}\text { Syndecan-1-mediated signaling } \\
\text { events }\end{array}$ & $4 \mathrm{E}-05$ & 8.7 & $\begin{array}{c}\text { COL1A1; COL3A1; COL5A1; COL14A1; COL6A2; } \\
\text { COL12A1; COL6A1; COL4A5 }\end{array}$ \\
\hline 13 & $\begin{array}{c}\text { Syndecan-4-mediated signaling } \\
\text { events }\end{array}$ & $2 \mathrm{E}-05$ & 8.5 & ACTN1; FN1; TNC; RAC1; F2; THBS1; RHOA \\
\hline 14 & $\begin{array}{l}\text { Urokinase-type plasminogen ac- } \\
\text { tivator (uPA) and uPAR-mediated } \\
\text { signaling }\end{array}$ & $1 \mathrm{E}-04$ & 7.0 & ITGAM; LRP1; ITGB2; FN1; ITGAV; RAC1; CTRC \\
\hline 15 & CDC42 signaling events & 7E-04 & 6.3 & $\begin{array}{c}\text { ACTR3; ARPC2; ARPC3; ARPC1B; CFL1; RAC1; } \\
\text { IQGAP1; PAK2 }\end{array}$ \\
\hline 16 & mTOR signaling pathway & $7 \mathrm{E}-04$ & 6.0 & $\begin{array}{c}\text { PDCD4; SFN; RAC1; EEF2; YWHAZ; PML; RHOA; } \\
Y W H A H\end{array}$ \\
\hline 17 & $\begin{array}{c}\text { HIF-1-alpha transcription factor } \\
\text { network }\end{array}$ & $5 \mathrm{E}-04$ & 5.1 & LDHA; TF; PKM; ITGB2; ENO1; CP; HK2; HK1 \\
\hline 18 & $\begin{array}{c}\text { Alpha4 beta1 integrin signaling } \\
\text { events }\end{array}$ & $2 \mathrm{E}-04$ & 3.8 & FN1; CD14; RAC1; TLN1; THBS1; YWHAZ \\
\hline 19 & Nectin adhesion pathway & $1 \mathrm{E}-04$ & 3.6 & RAP1A; ITGAV; RAC1; IQGAP1; TLN1; F11R \\
\hline 20 & CXCR4-mediated signaling events & $2 \mathrm{E}-03$ & 3.6 & $\begin{array}{c}\text { STAT1; CFL1; HLA-DRA; ITGAV; RAC1; RHOC; GNAI1; } \\
\text { RHOA; GNAI2 }\end{array}$ \\
\hline
\end{tabular}


Table 2. KEGG pathways enriched in PDAC

\begin{tabular}{|c|c|c|c|c|}
\hline No. & Term & $p$-value & $\begin{array}{l}\text { Combined } \\
\text { EnrichR } \\
\text { Score }\end{array}$ & Genes \\
\hline 1 & Phagosome & $4 \mathrm{E}-18$ & 68.4 & $\begin{array}{l}\text { STX12; ITGAM; RAB5C; TUBAL3; C1R; ITGB2; THBS1; CORO1A; } \\
\text { CTSS; ACTB; THBS4; THBS3; MRC2; C3; TUBB8; SEC61A1; TU- } \\
\text { BA1C; TUBB3; TUBB1; ITGAV; CD14; SEC61B; RAC1; TUBB; } \\
\text { HLA-B; HLA-A; TUBB2A; HLA-DRA; SEC22B; HLA-DRB1; TUBA8 }\end{array}$ \\
\hline 2 & $\begin{array}{l}\text { Complement and coagu- } \\
\text { lation cascades }\end{array}$ & $2 \mathrm{E}-16$ & 64.7 & $\begin{array}{c}\text { C1QB; ITGAM; SERPINA1; CFH; SERPINC1; C1R; F12; CFI; ITGB2; } \\
\text { F13A1; F2; C8B; KNG1; C4B; C3; C4A; C5; C8G; C7; CD55; CFB; } \\
\text { C1QC }\end{array}$ \\
\hline 3 & Metabolic pathways & $9 \mathrm{E}-14$ & 58.1 & $\begin{array}{c}\text { PNLIPRP1; PNLIPRP2; GPI; AMY2A; ADPGK; AMY2B; HEXB; } \\
\text { NDUFA10; PYGM; ABAT; ENO1; EPRS; ENO2; HK2; HK1; GMPPB; } \\
\text { NNT; IMPA2; NAPRT; GMPPA; DBT; NAMPT; AOX1; UQCRFS1; } \\
\text { PHGDH; HMGCS2; HIBCH; GAMT; PTGIS; PGAM2; SORD; CEL; } \\
\text { MAT1A; ALDH1A3; ALDH5A1; PKM; CHDH; RGN; SUCLG1; } \\
\text { LAP3; TKT; GAPDH; DLD; ALDH7A1; PNLIP; ALDH9A1; NNMT; } \\
\text { RPN2; PLA2G1B; MAOA; RPE; AK1; RPN1; COX5B; ACAT1; TYMP; } \\
\text { ADH4; LDHB; LDHA; ADSS; PCK2; FDPS; IDH3G; PTGES3; EPHX2; } \\
\text { SLC33A1; GFPT1; IDH2; ASNS; PYCR1; ALDH6A1; GATM; GNPDA1; } \\
\text { QARS; P4HA1; PSAT1; CTH; LPCAT2; SARDH; STT3A; ACO1; ADA; } \\
\text { PFKP }\end{array}$ \\
\hline 4 & $\begin{array}{l}\text { Glycolysis / Gluconeo- } \\
\text { genesis }\end{array}$ & $2 \mathrm{E}-13$ & 53.7 & $\begin{array}{c}\text { GPI; ADPGK; PGAM2; ENO1; ENO2; HK2; HK1; ALDH1A3; ADH4; } \\
\text { LDHB; LDHA; PKM; GAPDH; DLD; ALDH7A1; PFKP; ALDH9A1; } \\
\text { PCK2 }\end{array}$ \\
\hline 5 & $\begin{array}{l}\text { Regulation of actin } \\
\text { cytoskeleton }\end{array}$ & $4 \mathrm{E}-13$ & 50.8 & $\begin{array}{c}\text { CYFIP2; ITGAM; ARPC1B; ITGB2; IQGAP1; ACTB; MYL12A; } \\
\text { PPP1CC; CFL1; RAC2; PIP4K2A; MYH14; ITGAV; CD14; RAC1; } \\
\text { MYH10; PAK2; GSN; ACTN1; FN1; ARPC4; ACTN4; F2; RHOA; } \\
\text { ARPC2; ARPC3; MYH9; PFN1; MYL9; VCL }\end{array}$ \\
\hline 6 & Carbon metabolism & $7 \mathrm{E}-14$ & 50.3 & $\begin{array}{c}\text { GPI; ADPGK; IDH3G; RPE; IDH2; PGAM2; ENO1; ENO2; HK2; } \\
\text { ACAT1; HK1; ALDH6A1; PKM; PSAT1; RGN; ACO1; PHGDH; } \\
\text { SUCLG1; TKT; GAPDH; DLD; HIBCH; PFKP }\end{array}$ \\
\hline 7 & Focal adhesion & $5 \mathrm{E}-13$ & 49.5 & $\begin{array}{c}\text { FLT4; TNC; LAMC2; THBS1; ACTB; THBS4; MYL12A; THBS3; } \\
\text { PPP1CC; RAP1A; RAC2; FLNA; ITGAV; RAC1; PAK2; VASP; } \\
\text { LAMB3; ACTN1; FN1; ACTN4; RHOA; COL1A1; COL6A2; COL6A1; } \\
\text { COL4A5; GRB2; TLN1; MYL9; VCL }\end{array}$ \\
\hline 8 & Pancreatic secretion & $2 \mathrm{E}-13$ & 47.4 & $\begin{array}{l}\text { PNLIPRP1; CPA2; PNLIPRP2; CELA3A; CELA3B; CELA2A; CPA1; } \\
\text { PRSS1; CPB1; CELA2B; AMY2A; PLA2G1B; AMY2B; CEL; RHOA; } \\
\text { RAP1A; CTRL; RAC1; PRSS3; PRSS2; PNLIP }\end{array}$ \\
\hline 9 & $\begin{array}{l}\text { Pathogenic Escherichia } \\
\text { coli infection }\end{array}$ & $1 \mathrm{E}-12$ & 41.9 & $\begin{array}{l}\text { TUBAL3; TUBB; ARPC1B; ARPC4; YWHAZ; ACTB; RHOA; TUBB8; } \\
\text { TUBA1C; TUBB2A; ARPC2; ARPC3; TUBB3; TUBB1; CD14; TUBA8 }\end{array}$ \\
\hline 10 & $\begin{array}{l}\text { Protein digestion and } \\
\text { absorption }\end{array}$ & $5 \mathrm{E}-12$ & 37.7 & $\begin{array}{c}\text { CPA2; CELA3A; CELA3B; CELA2A; CPA1; PRSS1; CPB1; CELA2B; } \\
\text { COL14A1; COL12A1; COL1A1; COL3A1; COL5A1; CTRL; COL6A2; } \\
\text { COL6A1; COL4A5; PRSS3; PRSS2 }\end{array}$ \\
\hline 11 & $\begin{array}{l}\text { Biosynthesis of amino } \\
\text { acids }\end{array}$ & $2 \mathrm{E}-11$ & 36.0 & $\begin{array}{l}\text { IDH3G; RPE; IDH2; PGAM2; PYCR1; ENO1; MAT1A; ENO2; PKM; } \\
\text { PSAT1; CTH; ACO1; PHGDH; TKT; GAPDH; ALDH7A1; PFKP }\end{array}$ \\
\hline
\end{tabular}


Table 2. (Continued)

\begin{tabular}{|c|c|c|c|c|}
\hline No. & Term & $p$-value & $\begin{array}{c}\text { Combined } \\
\text { EnrichR } \\
\text { Score } \\
\end{array}$ & Genes \\
\hline 12 & $\begin{array}{l}\text { Staphylococcus aureus } \\
\text { infection }\end{array}$ & $2 \mathrm{E}-11$ & 33.9 & $\begin{array}{c}\text { C1QB; ITGAM; CFH; C1R; CFI; ITGB2; ICAM1; C4B; C3; C4A; C5; } \\
\text { HLA-DRA; CFB; HLA-DRB1; C1QC }\end{array}$ \\
\hline 13 & Ribosome & $2 \mathrm{E}-10$ & 32.2 & $\begin{array}{c}\text { RPS7; RPL12; RPS5; RPL22; RPS27L; RPSA; RPL8; RPL7; RPS25; } \\
\text { RPS14; RPS17; RPS28; RPS16; RPL18A; RPS3; RPL14; RPS20; RPS2; } \\
\text { RPS11; RPL28; RPS13 }\end{array}$ \\
\hline 14 & $\begin{array}{l}\text { Leukocyte transen- } \\
\text { dothelial migration }\end{array}$ & $5 \mathrm{E}-09$ & 26.1 & $\begin{array}{c}\text { VASP; ITGAM; MMP2; ACTN1; ITGB2; ACTN4; F11R; GNAI1; } \\
\text { ACTB; RHOA; MYL12A; GNAI2; ICAM1; RAP1A; RAC2; RAC1; } \\
\text { MYL9; VCL }\end{array}$ \\
\hline 15 & Amoebiasis & $2 \mathrm{E}-08$ & 25.9 & $\begin{array}{l}\text { ITGAM; RAB5C; LAMB3; ACTN1; ITGB2; FN1; SERPINB9; LAMC2; } \\
\text { ACTN4; C8B; COL1A1; COL3A1; C8G; COL4A5; CD14; VCL }\end{array}$ \\
\hline 16 & $\begin{array}{l}\text { Glycine, serine and } \\
\text { threonine metabolism }\end{array}$ & $6 \mathrm{E}-10$ & 25.0 & $\begin{array}{c}\text { GAMT; GATM; MAOA; PSAT1; CTH; CHDH; PGAM2; SARDH; } \\
\text { PHGDH; DLD; ALDH7A1; GNMT }\end{array}$ \\
\hline 17 & Pertussis & $2 \mathrm{E}-08$ & 21.8 & $\begin{array}{c}\text { C1QB; ITGAM; C1R; ITGB2; GNAI1; RHOA; GNAI2; C4B; C3; C4A; } \\
\text { C5; CFL1; CD14; C1QC }\end{array}$ \\
\hline 18 & $\begin{array}{l}\text { Protein processing in } \\
\text { endoplasmic reticulum }\end{array}$ & $1 \mathrm{E}-06$ & 18.4 & $\begin{array}{c}\text { HSPA5; RPN2; RPN1; RRBP1; EIF2S1; PDIA4; HSP90B1; SEC61A1; } \\
\text { DNAJB1; LMAN1; ERP29; STT3A; SSR1; HYOU1; SEC61B; P4HB; } \\
\text { UBQLN2; HSPA1A }\end{array}$ \\
\hline 19 & $\begin{array}{l}\text { Valine, leucine and iso- } \\
\text { leucine degradation }\end{array}$ & 7E-07 & 16.0 & $\begin{array}{c}\text { ALDH6A1; DBT; AOX1; ABAT; HMGCS2; DLD; ALDH7A1; HIBCH; } \\
\text { ALDH9A1; ACAT1 }\end{array}$ \\
\hline 20 & $\begin{array}{l}\text { ECM-receptor interac- } \\
\text { tion }\end{array}$ & $3 \mathrm{E}-06$ & 14.1 & $\begin{array}{c}\text { COL1A1; LAMB3; COL6A2; COL6A1; FN1; TNC; COL4A5; LAMC2; } \\
\text { ITGAV; THBS1; THBS4; THBS3 }\end{array}$ \\
\hline
\end{tabular}

blot. All PDAC cell lines tested expressed high level of PDGFR $\beta$ (Fig. 2D and E) confirming the prominent role of PDGFR $\beta$ signaling in both tumours and tumour-derived cultures.

Chronic pancreatitis is a chronic inflammatory process of the pancreas that shares some morphological and molecular features with PDAC. An in-depth proteomic analysis shows chronic pancreatitis as an intermediary condition between normal pancreatic tissue and pancreatic cancer (Ger et al., 2018). Alongside PDAC and healthy samples, tissue samples from ten patients with chronic pancreatitis were analysed as a control of unspecific inflammatory processes. In chronic pancreatitis we found 171 differentially regulated proteins; 156 proteins were increased, 15 proteins were decreased. While proteomic analysis shows some upregulation of ECM production and integrin signaling in chronic pancreatitis samples, these processes are significantly more prominent in PDAC samples. We have not detected change in PDGFR $\beta$, ILK, HIF- $1 \alpha$, and CXCR4 signaling pathways in chronic pancreatitis proving that upregulation of these processes is a specific feature of pancreatic cancer (data not shown).

In summary, the data shows that pancreatic cancer stimulates a variety of cell survivalrelated signaling pathways to develop chemotherapeutic drug resistance. The confirmed high expression of PDGFR $\beta$ receptor in primary cell cultures mirrors the importance of PDGFR $\beta$ signaling in PDAC tumours. Thus, we demonstrate that primary culture displays at least some of the defining features of pancreatic cancer suggesting primary cell culture as a valuable model for PDAC research. 


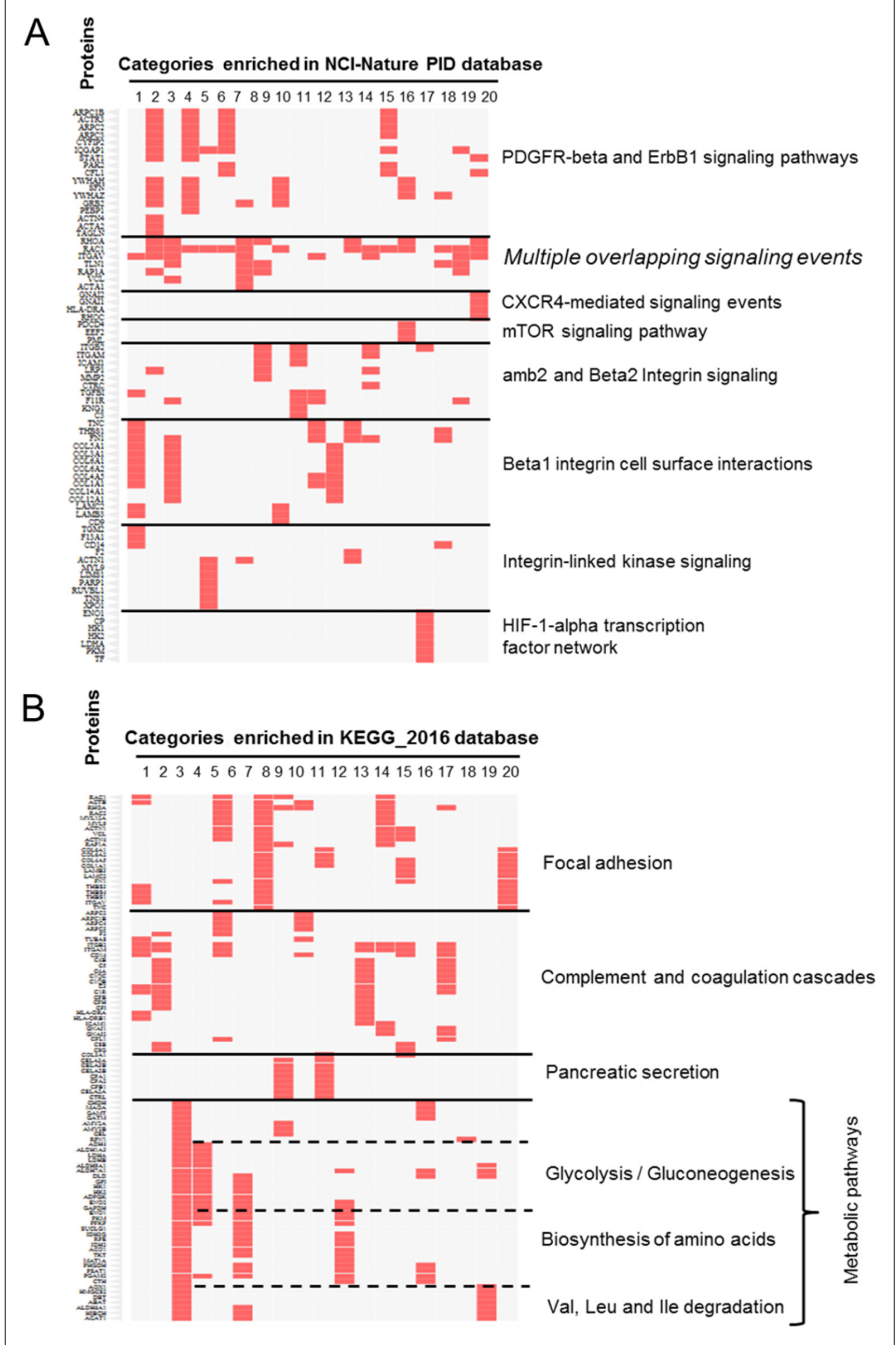




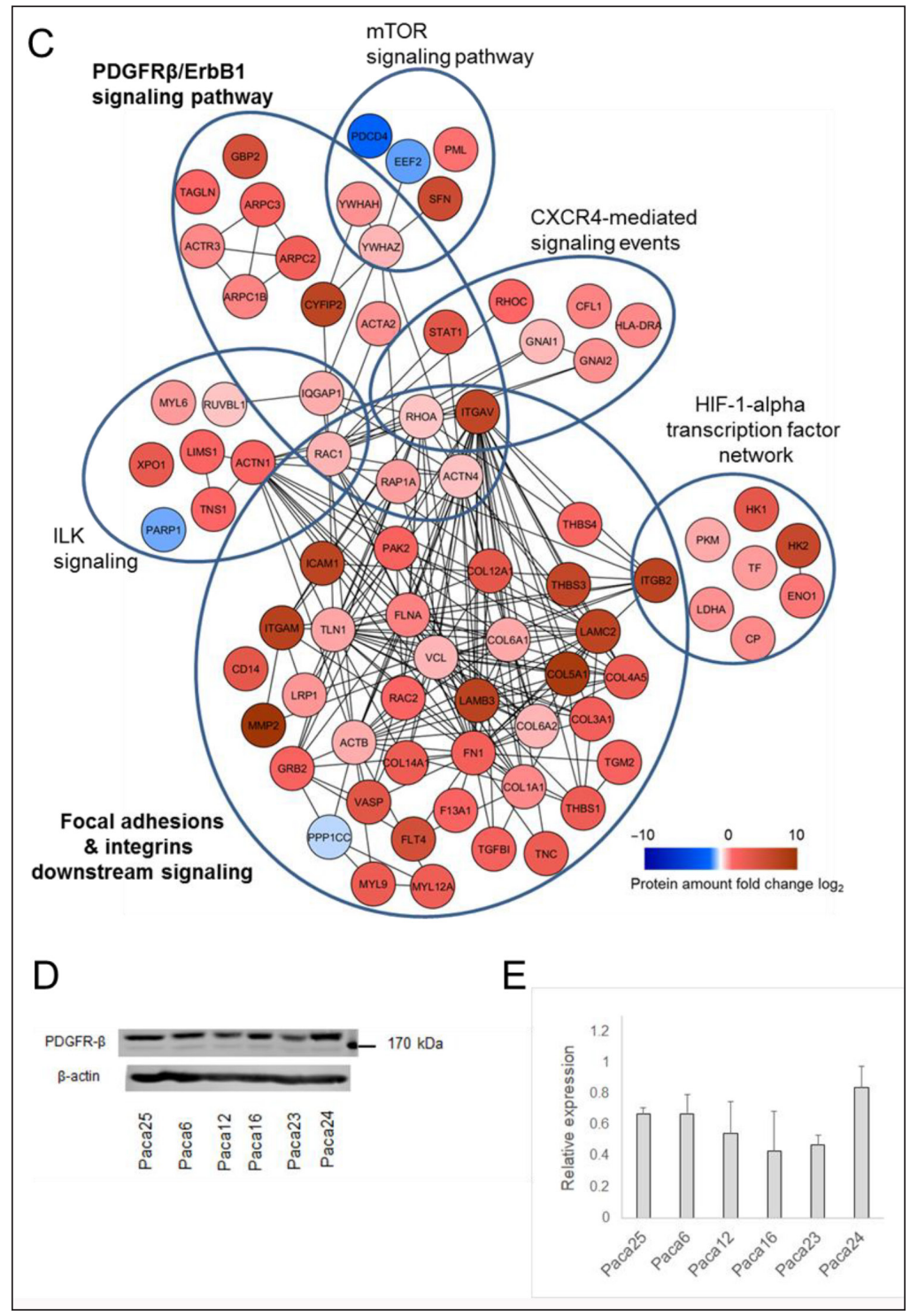

Fig. 2. Proteomic analysis of PDAC tissue samples reveals enhanced cell-ECM interaction and growth factor signaling pathways

A. Clustergram of PDAC-specific altered signaling pathways enriched using NCI-Nature PID database (see Table 1 for detailed information).

B. Clustergram of PDAC-specific altered metabolic and regulatory pathways enriched using KEGG_2016 database (see Table 2 for detailed information).

C. Protein differential expression, interaction and functional annotation network showing signaling pathways differentially regulated in PDAC compared to healthy pancreatic tissue.

D. Western Blot analysis of PDGFR- $\beta$ in Paca25, Paca6, Paca12, Paca16, Paca23 and Paca24 primary cell lines.

E. Quantification of (D). Relative protein expression was normalized according to $\beta$-actin expression.

\section{DISCUSSION}

Low efficiency of current chemotherapeutic approaches is one of the major reasons of high mortality among pancreatic cancer patients. In this study we demonstrated the resistance of primary PDAC patient-derived cell cultures to conventional treatments with gemcitabine or FOLFIRINOX. The high throughput proteomic analysis confirms the overexpression of components of multiple signaling pathways providing cell survival in PDAC.

In this study we show that primary PDAC cell culture derived from patients exhibits 
innate resistance to gemcitabine and FOLFIRINOX treatment. 5-fluorouracil fails to induce apoptosis in primary PDAC culture in contrast to the established pancreatic carcinoma cell line MiaPaCa-2, sensitive to 5 -fluorouracil treatment. Therapy resistance of patientderived cell cultures is in consistence with low response rate of gemcitabine reaching just up to $23 \%$ (Burris et al., 1997) and for FOLFIRINOX reaching up to 30\% (Conroy et al., 2011). Lately, established cancer cell lines have been widely criticized for a number of shortcomings, namely, genetic drift due to a long cultivation time in vitro, inability to represent the tumour heterogeneity, and even multiple cases of contamination with other cultures (Pan et al., 2009; Rückert et al., 2012). Moreover, native pancreatic tumour is characterized by extreme desmoplastic reaction causing the formation of dense stroma around the tumour (Hwang et al., 2008; Apte et al., 2004). The stroma not only serves as a mechanic barrier to anticancer compounds but also actively interacts with tumour cells modulating drug resistance, cell survival, epithelial-mesenchymal transition, and other malignant properties (Schnittert et al., 2019). That is why patientderived cell cultures at early passages represent tumour-specific processes more precisely than purified standardized tumour line. Established PDAC cell lines are widely used in research into tumour sensitivity to gemcitabine and other drugs (Fryer et al., 2011). The drawbacks of such cultures and discrepancy with intertumoural processes illustrated in this study must be taken into account in future drug research. Moreover, patient-derived tumour cell cultures provide a unique opportunity for personalized treatment selection (Kodack et al., 2017).

The in-depth comparative proteomic analysis reveals interplay of multiple signaling pathways upregulated in PDAC: extensive ECMintegrin expression and interaction, signaling downstream of PDGFR $\beta$, ErbB1, ILK, CXCR4, and HIF-1 $\alpha$ transcription factor. The most abundant group of proteins with altered expression clusters into overlapping signaling pathways of a variety of integrins interacting with ECM components. ECM overexpression and integrin-ECM interactions play a major role in providing elevated tumour drug resistance compared to isolated established cancer cell lines (Stein et al., 2004). The signaling of $\beta 1$-integrins enriched in our PDAC samples is known to provide radioprotection to pancreatic tumour cells by stimulating PI3K-AKT pathway (Hoshino et al., 2015). Another overexpressed set of regulatory pathways are signaling pathways from $\alpha \mathrm{M} \beta 2, \alpha 4 \beta 1, \alpha 6 \beta 1$, and $\alpha 6 \beta 4$ integrins. These integrins are known to provide cell adhesion and invasiveness by interaction with basement membrane laminin. Some of them also involved in a cooperative action with other signaling molecules, for example, $\alpha 6 \beta 4$ through interaction with ErbB2/HER2 receptor is required for $\mathrm{PI} 3 \mathrm{~K}$-dependent invasion (Gambaletta et al., 2000). We concurrently observe the abundance of PI3K-AKT pathway proteins in our dataset. In lung carcinoma exosomal a6 $\beta 4$ and $\alpha 6 \beta 1$ integrins were associated with metastatic formation (Hoshino et al., 2015). In summary, our data confirms the importance of ECM as a major factor in promoting PDAC progression and as a potential target for specific PDAC therapy (Weniger et al., 2018).

PDGFR $\beta$ in PDAC is expressed by tumour and stroma cells. In tumour cells, PDGFR $\beta$ drives pancreatic cancer invasion (Weissmueller et al., 2014). Higher expression of PDGFR $\beta$ in PDAC stroma is associated with patients' lower survival (Yuzawa et al., 2012). PDGFR $\beta$ ligand PDGF-BB is a strong mitogen and activator of pancreatic stellate cells (Luttenberger et al., 2000). Moreover, in pancreatic stellate cells activated PDGFR $\beta$ signals through phosphorylation of Erk causing cell proliferation and ECM production (Jaster et al., 2002). Thus PDGFR $\beta$ contributes to PDAC malignancy and drug resistance directly by driving tumour cell proliferation and invasion and indirectly by stimulating ECM production and ECM-related enhanced cell survival.

We also observe overexpression of ErbB1/ EGF receptor signaling pathway strongly overlapping with PDGFR $\beta$ signaling pathway. Overexpression and activation of EGF receptors 
is characteristic of pancreatic tumour cells and tumour microenvironment cells and may occur at the earliest stages of tumour development (Zhu et al., 2007; Day et al., 1996). Increased signaling from EGF family receptors results in enhanced cell proliferation, migration, and epithelial-mesenchymal transition (Lindsey, Langhans, 2015). Epithelial-mesenchymal transition plays fundamental roles in pancreatic cancer progression and drug resistance (Gaianigo et al., 2017).

\section{CONCLUSIONS}

Here we demonstrate that tumour-derived primary PDAC cell cultures exhibit innate resistance to chemotherapy drugs gemcitabine and FOLFIRINOX in contrast to the drug-sensitive established cell line MiaPaCa-2. In-depth proteomic analysis of tumour samples shows the overexpression of ECM components, of ECM-interacting integrins, and of downstream components of a variety of signaling pathways that may facilitate enhanced cell survival and drug resistance. In particular, the signaling pathway of PDGFR $\beta$ is enriched in PDAC tumour samples. Expression of PDGFR $\beta$ in primary cell cultures confirms the matching of primary cell lines with tumours. Thus, this work demonstrates that primary tumour-derived cell cultures could be a better model for PDAC biology research and drug evaluation than established cell lines. Moreover, implementation of tumourderived cell culture potentially facilitates drug selection for personalized patients' therapy and also should be utilized in the discovery of the advanced PDAC target therapy research.

\section{CONFLICTS OF INTEREST}

Authors declare that they have no conflicts of interest regarding this study.

\section{ACKNOWLEDGEMENTS}

This project was funded by "Healthy Ageing" programme of the Research Council of Lithu- ania (funding contract No. SEN-01/2016 / LSS150000-1269).

Received 18 March 2019

Accepted 11 April 2019

\section{References}

1. Apte MV, Park S, Phillips PA, Santucci N, Goldstein D, Kumar RK, et al. Desmoplastic reaction in pancreatic cancer: role of pancreatic stellate cells. Pancreas. 2004 Oct; 29(3): $179-87$.

2. Börner A, Warnken U, Schnölzer $\mathrm{M}, \mathrm{Ha}-$ gen J von, Giese N, Bauer A, et al. Subcellular protein extraction from human pancreatic cancer tissues. Biotechniques. 2009 Apr; 46(4): 297-304.

3. Burris HA, Moore MJ, Andersen J, Green MR, Rothenberg ML, Modiano MR, et al. Improvements in survival and clinical benefit with gemcitabine as first-line therapy for patients with advanced pancreas cancer: a randomized trial. J Clin Oncol. 1997 Jun; 15(6): 2403-13.

4. Conroy T, Desseigne F, Ychou M, Bouché O, Guimbaud R, Bécouarn Y, et al. FOLFIRINOX versus gemcitabine for metastatic pancreatic cancer. N Engl J Med. 2011 May 12; 364(19): 1817-25.

5. Day JD, Digiuseppe JA, Yeo C, Lai-Goldman M, Anderson SM, Goodman SN, et al. Immunohistochemical evaluation of HER-2/ neu expression in pancreatic adenocarcinoma and pancreatic intraepithelial neoplasms. Hum Pathol. 1996 Feb; 27(2): 119-24.

6. Ellenrieder V, König A, Seufferlein T. Current Standard and Future Perspectives in First- and Second-Line Treatment of Metastatic Pancreatic Adenocarcinoma. Digestion. 2016; 94(1): 44-9.

7. Fryer RA, Barlett B, Galustian C, Dalgleish AG. Mechanisms underlying gemcitabine resistance in pancreatic cancer and sensitisation by the iMiDTM lenalidomide. Anticancer Res. 2011 Nov; 31(11): 3747-56. 
8. Gaianigo N, Melisi D, Carbone C. EMT and treatment resistance in pancreatic cancer. Cancers (Basel). Multidisciplinary Digital Publishing Institute (MDPI); 2017 Sep 12; 9(9).

9. Gambaletta D, Marchetti A, Benedetti L, Mercurio AM, Sacchi A, Falcioni R. Cooperative signaling between alpha(6)beta(4) integrin and ErbB-2 receptor is required to promote phosphatidylinositol 3-kinase-dependent invasion. J Biol Chem. 2000 Apr 7; 275(14): 10604-10.

10. Ger M, Kaupinis A, Petrulionis M, Kurlinkus B, Cicenas J, Sileikis A, et al. Proteomic Identification of FLT3 and PCBP3 as Potential Prognostic Biomarkers for Pancreatic Cancer. Anticancer Res. 2018 Oct 1; 38(10): 5759-65.

11. Hwang RF, Moore T, Arumugam T, Ramachandran V, Amos KD, Rivera A, et al. CancerAssociated Stromal Fibroblasts Promote Pancreatic Tumor Progression. Cancer Res. 2008 Feb 1; 68(3): 918-26.

12. Hoff DD Von, Ervin T, Arena FP, Chiorean EG, Infante J, Moore $\mathrm{M}$, et al. Increased survival in pancreatic cancer with nab-paclitaxel plus gemcitabine. N Engl J Med. NIH Public Access; 2013; 369(18): 1691.

13. Hoshino A, Costa-Silva B, Shen T-L, Rodrigues G, Hashimoto A, Tesic Mark M, et al. Tumour exosome integrins determine organotropic metastasis. Nature. 2015 Nov 28; 527(7578): 329-35.

14. Jaster R, Sparmann G, Emmrich J, Liebe S. Extracellular signal regulated kinases are key mediators of mitogenic signals in rat pancreatic stellate cells. Gut. BMJ Publishing Group; 2002 Oct; 51(4): 579-84.

15. Kanehisa M, Sato Y, Kawashima M, Furumichi M, Tanabe M. KEGG as a reference resource for gene and protein annotation. Nucleic Acids Res. 2016 Jan 4; 44(D1): D457-62.

16. Kodack DP, Farago AF, Dastur A, Held MA, Dardaei L, Friboulet L, et al. Primary patientderived cancer cells and their potential for personalized cancer patient care. Cell Rep. 2017 Dec 12; 21(11): 3298-309.
17. Kuleshov MV, Jones MR, Rouillard AD, Fernandez NF, Duan Q, Wang Z, et al. Enrichr: a comprehensive gene set enrichment analysis web server 2016 update. Nucleic Acids Res. 2016 Jul 8; 44(W1): W90-7.

18. Lindsey S, Langhans SA. Epidermal growth factor signaling in transformed cells. Int Rev Cell Mol Biol. 2015; 314: 1-41.

19. Luttenberger T, Schmid-Kotsas A, Menke A, Siech M, Beger H, Adler G, et al. Plateletderived growth factors stimulate proliferation and extracellular matrix synthesis of pancreatic stellate cells: implications in pathogenesis of pancreas fibrosis. Lab Invest. 2000 Jan; 80(1): 47-55.

20. Pan C, Kumar C, Bohl S, Klingmueller U, Mann M. Comparative proteomic phenotyping of cell lines and primary cells to assess preservation of cell type-specific functions. Mol Cell Proteomics. 2009 Mar; 8(3): 443-50.

21. Rahib L, Smith BD, Aizenberg R, Rosenzweig AB, Fleshman JM, Matrisian LM. Projecting cancer incidence and deaths to 2030: the unexpected burden of thyroid, liver, and pancreas cancers in the United States. Cancer Res. 2014 Jun 1; 74(11): 2913-21.

22. Rückert F, Aust D, Böhme I, Werner K, Brandt A, Diamandis EP, et al. Five primary human pancreatic adenocarcinoma cell lines established by the outgrowth method. J Surg Res. 2012 Jan; 172(1): 29-39.

23. Saung MT, Zheng L. Current standards of chemotherapy for pancreatic cancer. Clin Ther. 2017 Nov; 39(11): 2125-34.

24. Schaefer CF, Anthony K, Krupa S, Buchoff J, Day M, Hannay T, et al. PID: the Pathway Interaction Database. Nucleic Acids Res. Oxford University Press; 2009 Jan; 37(Database issue): D674-9.

25. Schnittert J, Bansal R, Prakash J. Targeting pancreatic stellate cells in cancer. Trends in Cancer. 2019 Feb; 5(2): 128-42.

26. Shannon P, Markiel A, Ozier O, Baliga NS, Wang JT, Ramage D, et al. Cytoscape: a software environment for integrated models of 
biomolecular interaction networks. Genome Res. 2003 Nov; 13(11): 2498-504.

27. Siegel RL, Miller KD, Jemal A. Cancer statistics, 2018. CA Cancer J Clin. 2018 Jan; 68(1): 7-30.

28. Stein WD, Litman T, Fojo T, Bates SE. A Serial Analysis of Gene Expression (SAGE) database analysis of chemosensitivity: comparing solid tumors with cell lines and comparing solid tumors from different tissue origins. Cancer Res. 2004 Apr 15; 64(8): 2805-16.

29. Zhu L, Shi G, Schmidt CM, Hruban RH, Konieczny SF. Acinar cells contribute to the molecular heterogeneity of pancreatic intraepithelial neoplasia. Am J Pathol. 2007 Jul; 171(1): 263-73.

30. Yuzawa S, Kano MR, Einama T, Nishihara H. PDGFR $\beta$ expression in tumor stroma of pancreatic adenocarcinoma as a reliable prognostic marker. Med Oncol. 2012 Dec 9; 29(4): 2824-30.

31. Warde-Farley D, Donaldson SL, Comes O, Zuberi K, Badrawi R, Chao P, et al. The GeneMANIA prediction server: biological network integration for gene prioritization and predicting gene function. Nucleic Acids Res. 2010 Jul; 38(Web Server issue): W214-20.

32. Weniger M, Honselmann KC, Liss AS. The extracellular matrix and pancreatic cancer: a complex relationship. Cancers (Basel). 2018 Sep 6; 10(9): 316.

33. Weissmueller S, Manchado E, Saborowski M, Morris JP, Wagenblast E, Davis CA, et al. Mutant p53 drives pancreatic cancer metastasis through cell-autonomous PDGF receptor $\beta$ signaling. Cell. 2014 Apr 10; 157(2): 382-94.
Marija Ger, Eglè Žalytė, Algirdas Kaupinis, Benediktas Kurlinkus, Marius Petrulionis, Audrius Šileikis, Kęstutis Strupas, Mindaugas Valius

\section{PIRMINĖS KASOS DUKTALINĖS ADENO- KARCINOMOS LĄSTELIŲ KULTŪROS AT- SPINDI NATYVIŲ NAVIKŲ SAVYBES}

\section{Santrauka}

Kasos duktalinė adenokarcinoma (KDA) yra vėžio tipas, pasižymintis vienu aukščiausiu mirštamumu dèl diagnostikos ankstyvoje ligos stadijoje ịrankių stokos ir neefektyvių dabartinių chemoterapijos priemonių. Standartizuotose ląstelių kultūrose nustatyto priešvèžinių preparatų veiksmingumo tolesni tyrimai neretai nepatvirtina. Šiame darbe chemoterapijos preparatų efektyvumui įvertinti mes panaudojome pirmines ląstelių kultūras, išskirtas iš KDA pacientų pooperacinès medžiagos. Buvo atlikta ir pooperacinių méginių aukšto pajėgumo diferencinè proteominè analizè. Mes nustatème, jog standartiniai pirmos eilès chemoterapijos preparatai neveikia arba beveik neveikia pirminių KDA ląstelių kultūrų. Lyginamoji proteominè ir bioinformatinė KDA navikų analizė išryškino didesnę užląstelinio užpildo, fokalinių adhezijų komponentų ir ịvairių receptorių signalinių kelių komponentų raišką, ypač PDGF $\beta$ receptoriaus bei ErbB1 receptoriaus. Visos patikrintos pirminès ląstelių linijos pasižymi didele PDGF $\beta$ receptoriaus raiška. Daugybinių signalinių kelių aktyvacija lemia didesnị ląstelių išgyvenamumą, proliferaciją bei atsparumą apoptozei. Šiame darbe mes atskleidème KDA pacientų pirminių ląstelių kultūrų kaip modelio priešvèžinių vaistų tyrimams bei įvertinimui vertę.

Raktažodžiai: kasos véžys, pirminè pacientų ląstelių kultūra, trombocitų kilmès augimo veiksnio receptorius, atsparumas priešvèžiniams vaistams 